\title{
Prediction of Time to Delivery Week-by-Week in Women with a Triplet Pregnancy
}

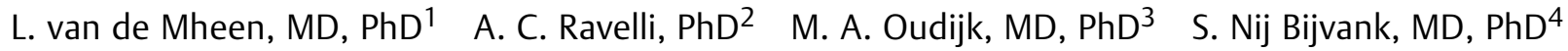

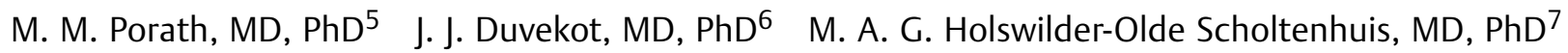 \\ K. W. M. Bloemenkamp, MD, $\mathrm{PhD}^{8} \quad$ H. C. J. Scheepers, MD, PhD ${ }^{9}$ M. Woiski, MD, PhD ${ }^{10}$ \\ $\begin{array}{llll}\text { M. G. van Pampus, MD, PhD } & \text { C. J. de Groot, MD, PhD } & \text { E. Pajkrt, MD, PhD } & \text { B. W. J. Mol, MD, PhD } \\ & 12\end{array}$
}

${ }^{1}$ Department of Obstetrics and Gynecology, VU University Medical

Address for correspondence L. van de Mheen, MD, PhD, Department Center, Amsterdam, The Netherlands

${ }^{2}$ Department of Medical Informatics, Academic Medical Center, Amsterdam, The Netherlands

${ }^{3}$ Department of Obstetrics and Gynecology, Academic Medical 7057, 1007 MB Amsterdam, The Netherlands

Center, Amsterdam, The Netherlands

${ }^{4}$ Department of Obstetrics and Gynecology, Isala Clinics, Zwolle,

The Netherlands

${ }^{5}$ Department of Obstetrics and Gynecology, Maxima Medical Center, Veldhoven, The Netherlands

${ }^{6}$ Department of Obstetrics and Gynecology, Erasmus MC, University Medical Center, Rotterdam, The Netherlands

${ }^{7}$ Department of Obstetrics and Gynecology, University Medical Center Groningen, University of Groningen, Groningen, The Netherlands

8 Department of Obstetrics and Gynecology, University Medical Center Utrecht, Utrecht, The Netherlands

${ }^{9}$ Department of Obstetrics and Gynecology, Maastricht University Medical Center, Maastricht, The Netherlands

10 Department of Obstetrics and Gynecology, Radboud University Medical Center, Nijmegen, The Netherlands

${ }^{11}$ Department of Obstetrics and Gynecology, Onze Lieve Vrouwe Gasthuis, Amsterdam, The Netherlands

${ }^{12}$ School of Paediatrics and Reproductive Health, The Robinson Institute, Adelaide, Australia

Am J Perinatol 2016;33:1394-1400.
Abstract
Keywords
- triplet pregnancy
- preterm birth
- antenatal steroid treatment
- neonatal outcome

Objective Some clinicians advise prophylactic administration of antenatal steroids for fetal lung maturation in women with a triplet pregnancy. However, the effect of corticosteroids is limited to 10 to 14 days after administration. The aim of this study was to assess the natural course of triplet pregnancies to allow a better anticipation for administration of corticosteroids.

Study Design We collected data on all triplet pregnancies in the Netherlands from 1999 to 2007 from the Netherlands Perinatal Registration. We calculated time to delivery, the risk of delivery in 2-week intervals at different gestational ages, and the time frame between hospital admission and delivery of the first child.

Results Median gestational age at delivery of 494 women with a triplet pregnancy was $33^{+4}$ weeks (interquartile range of $31-35^{+1}$ weeks). Twenty-one women (4.3\%) delivered between 22 and 24 weeks and 146 women (29.6\%) delivered before 32 weeks. At a gestational age of 24 weeks, the chance to deliver within the next week was $0.6 \%$. received

November 25, 2015

accepted after revision

February 26, 2016

published online

May 11, 2016
Copyright $\odot 2016$ by Thieme Medical Publishers, Inc., 333 Seventh Avenue, New York, NY 10001, USA. Tel: +1(212) 584-4662.
DOI http://dx.doi.org/ 10.1055/s-0036-1583190. ISSN 0735-1631. 
For $26,28,30,31$, and 32 weeks, these risks were $2.4,2.5,8.1,7$, and $16.7 \%$, respectively.

Conclusion Before 32 weeks of gestation, prophylactic administration of steroids is not indicated as the risk to deliver within 7 days is $<10 \%$.

Triplet pregnancies are rare, but still its incidence has risen from 1,000 to more than 7,000 in the United States between 1980 and 2005. This is due to the increased use of assisted reproductive techniques and increasing maternal age. ${ }^{1-4}$ Triplet pregnancies are associated with a higher incidence of maternal morbidity during pregnancy and labor ${ }^{2,5}$ and with more neonatal morbidity and mortality as compared with women with a singleton or twin pregnancy. Neonatal morbidity and mortality in triplets are mainly due to prematurity. ${ }^{2,6-9}$ It has been shown that the mean gestational age at delivery in women with a triplet pregnancy is approximately 32 weeks and has been stable since the 1980 s., ${ }^{3,10}$ However, some studies show that gestational age at delivery has decreased from 34 to 32 weeks, ${ }^{4,11}$ thereby steadily increasing the absolute rate of preterm birth from $80-90$ to $96 \%{ }^{3,12}$

Antenatal administration of corticosteroids to women with threatened preterm labor or medical or fetal complications that are likely to require delivery (preeclampsia, intrauterine growth restriction) is proven to diminish neonatal mortality and morbidity in preterm born children by reducing respiratory distress syndrome, sepsis, necrotizing enterocolitis, and cerebral hemorrhage. ${ }^{13}$ However, predicting whether a woman with a triplet pregnancy will deliver (very) preterm remains a clinical challenge. In asymptomatic women with a triplet gestation, only short cervical length (CL) and fetal fibronectin (fFN) tests have been demonstrated to be predictive for preterm birth $<32$ weeks. ${ }^{14-17}$ Prophylactic therapies such as cervical cerclage, pessary placement, and administration of progesterone do not seem to be beneficial in decreasing the amount of preterm births and its accompanying neonatal mortality and morbidity. ${ }^{18-20}$ Some clinicians advise prophylactic administration of corticosteroids to all women with a triplet pregnancy for acceleration of fetal lung matuartion, ${ }^{9,21}$ irrespective of signs and symptoms that could announce preterm delivery. However, there is lack of evidence to support this practice. 22,23

Accurate prediction of preterm birth in triplets would be valuable for the ideal timing of the administration of prophylactic steroids because the optimal effect lies between 48 hours and 7 days before delivery. ${ }^{13}$ We evaluated the natural course of triplet pregnancies by calculating the risk of delivery in a particular time frame during gestation. Moreover, we analyzed the time frame between the admission of a pregnant woman with a triplet pregnancy to the hospital and delivery of the first child. The aim of this study was to examine if, in triplet pregnancies, we could identify the optimal gestational age, in which prophylactic administration of steroids would be useful.

\section{Patients and Methods}

In this retrospective cohort study, we collected data of all triplet pregnancies in the Netherlands during the period of
1999 to 2007. The triplet pregnancies were selected from the Netherlands Perinatal Registration (PRN) ${ }^{24}$ by the variables "multiple births" and "size three." The registry was used to select the hospitals where, after permission of the hospital, additional data for each triplet pregnancy was collected from the medical records. The PRN collects all data regarding pregnancy outcome, maternal and neonatal outcome in the Netherlands starting at a gestational age of 22 weeks. Data regarding gestational age at delivery, conception mode, maternal age, parity, ethnicity, induction of labor, mode of delivery, birth weight, and neonatal morbidity and mortality were collected. Conception mode was registered as spontaneous or with use of assisted reproductive technologies, including ovulation induction, intrauterine insemination, in vitro fertilization, and parity as nulliparous or multiparous. Start of labor was classified as spontaneous, induction of labor, or planned cesarean delivery. Mode of delivery was classified as planned cesarean section, emergency cesarean section, or vaginal delivery, including assisted vaginal delivery. Neonatal morbidity included sepsis, intraventricular hemorrhage, infant respiratory distress syndrome, and bronchopulmonary dysplasia. Perinatal mortality was recorded as fetal mortality (intrauterine fetal demise or demise during delivery) or neonatal mortality in the first 28 days after delivery. As the PRN does not register reliable information concerning chorionicity and hospital admission time of the mother, we collected these data from individual hospital records or digital hospital information systems. Chorionicity was based on first trimester ultrasound or was determined postdelivery after histological assessment of the placenta by a pathologist. In cases that were recorded as monochorionic, it was not always possible to distinguish between a monochorionic triplet and a monochorionic twin with a singleton alongside which actually should be recorded as a dichorionic triplet. Therefore, we analyzed chorionicity as trichorionic or monochorionic where the latter included any triplet that contained a monochorionic component. We collected time and date of maternal admission to the hospital directly before delivery. If only the date of admission was available, but not the exact time, we set admission time as 12 PM.

All women with a pregnancy recorded as a triplet in the national registry were included in the study. Exclusions for fetal demise or congenital abnormalities were not made. Pregnancies registered in the PRN as a triplet from whom only information on one or two fetuses could be obtained were excluded from the study, as it was not possible to distinguish between a triplet pregnancy and an administrative fault. Before exclusion, these pregnancies were matched with other pregnancies with missing fetuses, to be sure there was no interval delivery of the same mother in a different hospital, but no such cases were found. 
Primary outcomes in the study were time to delivery and the risk of delivery in a particular time frame of 1 and 2 weeks. Subgroup analyses were made for parity and chorionicity in relation to the primary outcome. As we had no reliable information about the actual administration of antenatal corticosteroids, we used duration of maternal hospitalization as a surrogate outcome. We considered a hospitalization of $\geq 48$ hours before the delivery of the first child as sufficient. As a secondary outcome, we analyzed the relation between duration of maternal hospitalization and neonatal morbidity and mortality.

\section{Statistical Analysis}

We constructed a Kaplan-Meier curve for time to delivery in the whole study group, starting from 22 weeks onward. We calculated the risk of delivery within 1 and 2 weeks for different gestational ages by subtracting the number of women who delivered in a time frame from all women who were still pregnant at the beginning of that time frame. We calculated these risks for time frames of 1 and 2 weeks, as the first is the optimal period that antenatal corticosteroids are assumed to work ${ }^{13}$ and the second because this is the minimum interval that is recommended in our national guidelines between two courses of corticosteroids. ${ }^{25}$ The duration of hospitalization was calculated by the time between hospital admission before delivery and the birth date and time of the first child. We considered hospital admission to be sufficient if an interval of at least 48 hours was achieved, in patients with a delivery before 34 weeks' gestation. Fisher exact test or chi-square test were used for categorical data, and one way analysis of variance or Kruskal-Wallis tests were used for numeric data depending on the normal distribution of the variables. Statistical analysis was performed in Statistical Package for Social Sciences (SPSS, Armonk, NY) version 20.

\section{Results}

In the study period, 575 pregnancies were registered as a triplet pregnancy in the PRN, of which 81 could not be confirmed as a triplet and were excluded as administrative mistakes. - Table 1 shows baseline characteristics of the 494 triplet pregnancies included in our study. Median gestational age at delivery was 33 weeks and 4 days with an interquartile range of 31 to $35^{+1}$ weeks. Twenty-one women (4.3\%) delivered between 22 and 24 weeks, 146 women delivered before 32 weeks (29.6\%), and 269 women before 34 weeks (54.5\%). Sixteen women (3.2\%) delivered after 37 weeks. - Table 2 shows the risk of delivery within 1 or 2 weeks for each week of pregnancy. At a gestational age of 24 weeks, the chance of delivering within the next week was $0.6 \%$. For $26,28,30$, and 32 weeks, these risks were $2.4,2.5,8.1$, and $16.7 \%$, respectively. - Fig. 1 shows a Kaplan-Meier curve for time to delivery in women with a triplet pregnancy.

In 16 women (3.2\%), delivery of the second child was postponed after the first child was born by at least 24 hours, with a maximum interval of 16 days. In all these women, the second and third children were born within a short interval.

Data regarding chorionicity were available for 393 (79.5\%) of women. Median gestational age at delivery was longer for trichorionic triplets compared with triplets containing a monochorionic component $\left(33^{+6}\right.$ vs. $33^{+0}$ weeks, respectively, $p=0.02$ ). Multiparous women had a longer median gestational age compared with nulliparous women $\left(34^{+0}\right.$ vs. $33^{+1}$ weeks, respectively, $p=0.02$ ). Gestational age of delivery was independent from mode of conception $(p=0.07)$. - Fig. 2 shows time to delivery stratified by chorionicity and parity. - Table 2 shows the risks of delivery within 1 or 2 weeks for each combination of chorionicity and parity. For nulliparous women with a mono- or dichorionic

Table 1 Baseline characteristics

\begin{tabular}{|c|c|c|c|c|c|c|c|}
\hline & $\begin{array}{l}\text { Total group } \\
(n=494)\end{array}$ & $\begin{array}{l}\text { Delivery } \\
<34 \text { wk } \\
(n=269)\end{array}$ & $\begin{array}{l}\text { Delivery } \\
\geq 34 \text { wk } \\
(n=225)\end{array}$ & $p$-Value & $\begin{array}{l}\text { Delivery } \\
<32 \text { wk } \\
(n=146)\end{array}$ & $\begin{array}{l}\text { Delivery } \\
\geq 32 \text { wk } \\
(n=348)\end{array}$ & $p$-Value \\
\hline Maternal age & $32.1(4.3)$ & $31.7(4.5)$ & $32.5(4.1)$ & 0.04 & $31.1(4.6)$ & $32.5(4.1)$ & 0.002 \\
\hline Nulliparity & $274(55.5)$ & $164(60.9)$ & $110(48.9)$ & 0.005 & $101(69.2)$ & $173(49.7)$ & $<0.001$ \\
\hline $\begin{array}{l}\text { Spontaneous } \\
\text { conception }^{\text {a }}\end{array}$ & $114 / 312(36.5)$ & $67 / 167(40.1)$ & $47 / 145$ (32.4) & 0.09 & $28 / 82(34.1)$ & $86 / 230(37.4)$ & 0.4 \\
\hline Dutch ethnicity & $406(82.2)$ & $228(84.8)$ & $178(79.1)$ & 0.06 & $125(85.6)$ & $281(80.7)$ & 0.1 \\
\hline Trichorionic $^{a}$ & $202 / 393(51.4)$ & $101 / 218(46.3)$ & $101 / 175(57.7)$ & 0.01 & $52 / 117(44.4)$ & $150 / 276(54.4)$ & 0.04 \\
\hline $\begin{array}{l}\text { Admission } \\
\geq 48 \mathrm{~h}^{\mathrm{a}}\end{array}$ & $220 / 390(56.4)$ & $119 / 216(55.1)$ & $101 / 174(58)$ & 0.3 & $59 / 116(50.9)$ & $161 / 274(58.8)$ & 0.09 \\
\hline $\begin{array}{l}\text { Spontaneous } \\
\text { onset of labor }\end{array}$ & $155(31.4)$ & $121(45)$ & $34(15.1)$ & $<0.001$ & $88(60.2)$ & 67 (19.3) & $<0.001$ \\
\hline Vaginal delivery & $124(25.1)$ & 85 (31.6) & $39(17.3)$ & $<0.001$ & $60(41.1)$ & $64(18.4)$ & $<0.001$ \\
\hline $\begin{array}{l}\text { Hypertensive } \\
\text { disorder }\end{array}$ & $77(15.6)$ & $41(15.2)$ & $36(16)$ & 0.5 & $14(9.6)$ & $63(18.1)$ & 0.01 \\
\hline
\end{tabular}

Note: Data presented as mean (standard deviation), number (\%), or median (interquartile range).

${ }^{a}$ Due to missing data, denominator does not equal total study group. 
Table 2 Risk to deliver in a particular time frame

\begin{tabular}{|c|c|c|c|c|c|c|c|c|c|c|}
\hline \multirow[b]{2}{*}{$\begin{array}{l}\text { Gestational } \\
\text { age (wk) }\end{array}$} & \multicolumn{2}{|c|}{$\begin{array}{l}\text { All triplets } \\
N=494^{\mathrm{a}}\end{array}$} & \multicolumn{2}{|c|}{$\begin{array}{c}\text { TC-P0 } \\
N=113^{\mathrm{a}}\end{array}$} & \multicolumn{2}{|c|}{$\begin{array}{c}\text { TC-P1 } \\
N=89^{\mathrm{a}}\end{array}$} & \multicolumn{2}{|c|}{$\begin{array}{c}\text { MC-P0 } \\
N=109^{\mathrm{a}}\end{array}$} & \multicolumn{2}{|c|}{$\begin{array}{c}\text { MC-P1 } \\
N=82^{\mathrm{a}}\end{array}$} \\
\hline & $\begin{array}{l}\text { Risk to } \\
\text { deliver } \\
<1 \text { wk } \\
(\%)\end{array}$ & $\begin{array}{l}\text { Risk to } \\
\text { deliver } \\
<2 \text { wk } \\
(\%)\end{array}$ & $\begin{array}{l}\text { Risk to } \\
\text { deliver } \\
<1 \text { wk } \\
\text { (\%) }\end{array}$ & $\begin{array}{l}\text { Risk to } \\
\text { deliver } \\
<2 \text { wk } \\
\text { (\%) }\end{array}$ & $\begin{array}{l}\text { Risk to } \\
\text { deliver } \\
<1 \text { wk } \\
\text { (\%) }\end{array}$ & $\begin{array}{l}\text { Risk to } \\
\text { deliver } \\
<2 \text { wk } \\
(\%)\end{array}$ & $\begin{array}{l}\text { Risk to } \\
\text { deliver } \\
<1 \mathrm{wk} \\
(\%)\end{array}$ & $\begin{array}{l}\text { Risk to } \\
\text { deliver } \\
<2 \text { wk } \\
(\%)\end{array}$ & $\begin{array}{l}\text { Risk to } \\
\text { deliver } \\
<1 \text { wk } \\
(\%)\end{array}$ & $\begin{array}{l}\text { Risk to } \\
\text { deliver } \\
<2 \text { wk } \\
(\%)\end{array}$ \\
\hline 24 & 0.6 & 2.3 & 1.0 & 5.7 & 1.1 & 2.3 & 0 & 2.9 & 1.2 & 3.7 \\
\hline 25 & 1.7 & 4.1 & 4.8 & 6.7 & 0 & 1.2 & 2.9 & 4.9 & 0 & 2.5 \\
\hline 26 & 2.4 & 5.6 & 2.0 & 9.1 & 1.2 & 2.3 & 2 & 5 & 2.5 & 3.7 \\
\hline 27 & 3.3 & 5.8 & 7.2 & 9.3 & 1.2 & 2.4 & 3.1 & 7.1 & 1.3 & 5.1 \\
\hline 28 & 2.5 & 6.7 & 2.2 & 7.8 & 1.2 & 2.4 & 4.2 & 10.5 & 3.8 & 6.4 \\
\hline 29 & 4.2 & 12 & 5.7 & 9. 1 & 1.2 & 4.8 & 6.6 & 17.9 & 2.7 & 20.0 \\
\hline 30 & 8.1 & 14.5 & 3.6 & 12.0 & 3.7 & 6.1 & 11.8 & 22.4 & 17.9 & 32.9 \\
\hline 31 & 7 & 22.5 & 8.8 & 21.1 & 2.5 & 15.2 & 12.0 & 32.0 & 0 & 18.3 \\
\hline 32 & 16.7 & 35.3 & 13.7 & 34.2 & 13.0 & 31.2 & 22.7 & 42.4 & 18.3 & 40.0 \\
\hline 33 & 22.4 & 50.7 & 23.8 & 46.0 & 20.9 & 52.2 & 25.5 & 56.9 & 26.5 & 49.0 \\
\hline 34 & 36.4 & 75.1 & 29.2 & 68.8 & 39.6 & 75.5 & 42.1 & 78.9 & 30.6 & 88.9 \\
\hline 35 & 60.8 & 88.8 & 55.9 & 88.2 & 59.4 & 87.5 & 63.6 & 86.4 & 84 & 100 \\
\hline 36 & 71.4 & 96.4 & 73.3 & 100 & 69.2 & 92.3 & 62.5 & 87.5 & 100 & 100 \\
\hline
\end{tabular}

Abbreviations: $\mathrm{MC}$, monochorionic; $\mathrm{P} 0$, nulliparous; $\mathrm{P} 1$, parous; $\mathrm{TC}$, trichorionic.

${ }^{a}$ Sum of groups does not equal total due to missing variables $(n=101)$.

triplet pregnancy, the risks of delivery within 1 week were $4.2 \%$ at 28 weeks, $11.8 \%$ at 30 weeks, $12 \%$ at 31 weeks, and $22.7 \%$ at 32 weeks of gestation.

Time of hospital admission was available for 390 patients (78.9\%) Of these women, 220 (56.4\%) had been admitted for more than 48 hours before their delivery. Neonatal outcomes are shown in - Table 3. Of all 494 women, 420 (85\%) had three surviving children, while 25 (5.1\%) lost all three children. Adverse neonatal outcome occurred in 428 of 1,482 children (28.9\%). Neonatal morbidity and adverse neonatal outcome were not different between women who had been admitted for more than 48 hours (-Fig. 3) or those who were not.

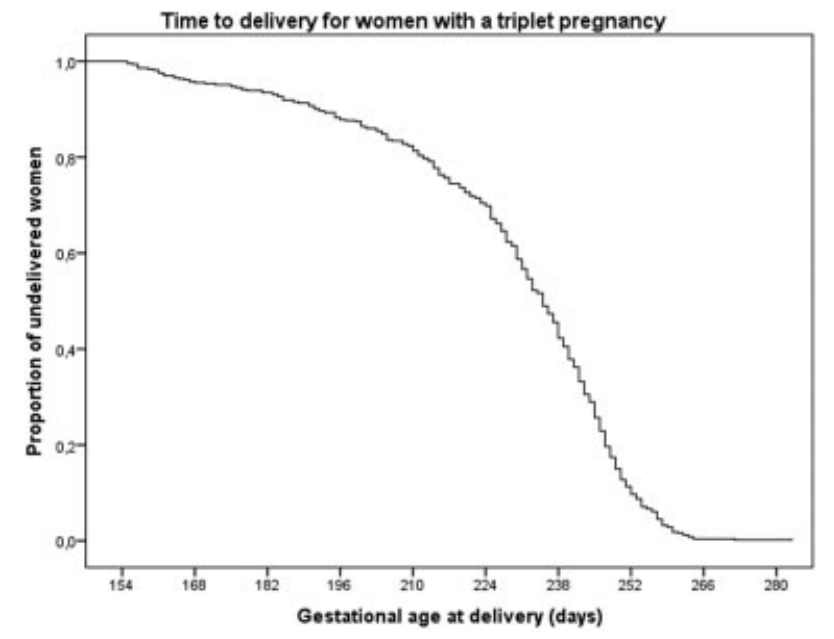

Fig. 1 Kaplan-Meier curve for time to delivery in women with a triplet pregnancy.
Neonatal death was the only outcome which differed significantly in these women ( 7.4 vs. $12.9 \%$, respectively, $p=0.04$ ).

\section{Discussion}

In this retrospective study, we showed that median gestational age at delivery in women with a triplet pregnancy was $33^{+4}$ weeks. Our objective was to evaluate if, in women with a triplet pregnancy, there is one gestational age with such a high risk of delivering within 1 week to warrant a prophylactic (i.e., without symptoms of preterm labor) course of corticosteroids to all women with a triplet pregnancy.

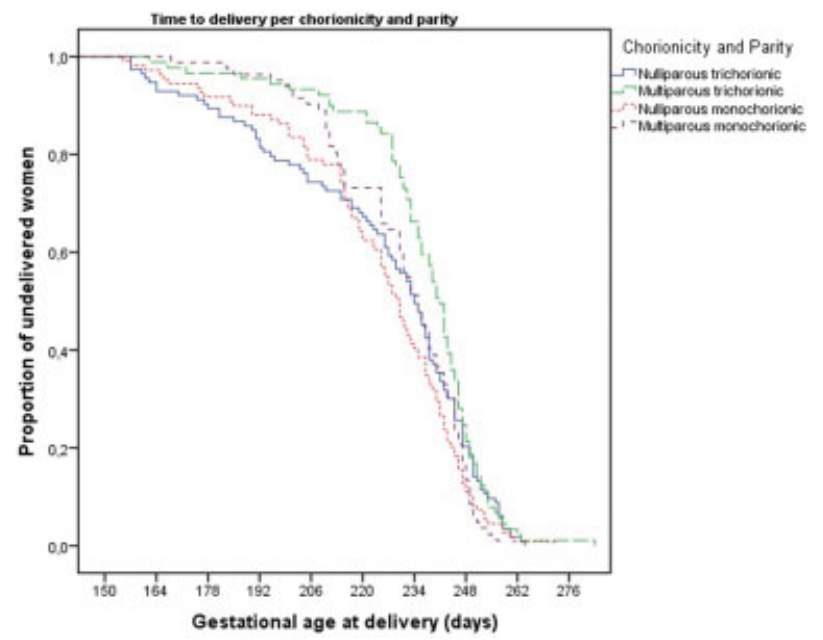

Fig. 2 Time to delivery stratified by chorionictiy and parity. 
Table 3 Neonatal outcome

\begin{tabular}{|c|c|c|c|c|}
\hline & Total group & Admission $<48 \mathrm{~h}$ & Admission $\geq 48 \mathrm{~h}$ & $p$-Value \\
\hline Per pregnancy & $N=494$ & $N=170(43.6)$ & $N=220(56.4)$ & \\
\hline Gestational age at delivery & 235 (IQR 217-246) & $233(214-245)$ & $236(220-246)$ & 0.5 \\
\hline Women without surviving children & $25(5.1)$ & $13(7.6)$ & $7(3.2)$ & 0.06 \\
\hline One survivor & $16(3.2)$ & $6(3.5)$ & $7(3.2)$ & 1 \\
\hline Two survivors & $33(6.7)$ & $15(8.8)$ & $14(6.4)$ & 0.4 \\
\hline Three survivors & $420(85)$ & $136(80)$ & $192(87.3)$ & 0.07 \\
\hline Per child & $N=1,482$ & $N=510(43.6)$ & $N=660(56.4)$ & \\
\hline Birth weight $(g)$ & $1,799(1,325-2,174)$ & $1,778(1,290-2,181)$ & $1,795(1,329-2,170)$ & 0.7 \\
\hline Admission to NICU & $409(27.6)$ & $143(28)$ & $199(30.2)$ & 0.4 \\
\hline Congenital abnormality & $58(3.9)$ & $24(4.7)$ & $23(3.5)$ & 0.3 \\
\hline Neonatal morbidity $^{a}$ & $309(20.9)$ & $108(21.2)$ & $150(22.7)$ & 0.6 \\
\hline Low 5-min Apgar score $(<7)$ & $165(11.1)$ & $68(13.3)$ & $65(9.8)$ & 0.06 \\
\hline Fetal demise & $77(5.2)$ & $36(7.1)$ & $29(4.4)$ & 0.5 \\
\hline Neonatal death & $63(4.3)$ & 66 (12.9) & $49(7.4)$ & 0.04 \\
\hline Adverse neonatal outcome ${ }^{\mathrm{b}}$ & $428(28.9)$ & $165(32.4)$ & $191(28.9)$ & 0.2 \\
\hline
\end{tabular}

Abbreviations: BPD, bronchopulmonary dysplasia; IRDS, infant respiratory distress syndrome; IVH, intraventricular hemorrhage; NICU, neonatal intensive care unit.

Note: Data presented as median (interquartile range) or number (\%).

ancludes sepsis, IRDS, BPD, and IVH.

${ }^{\mathrm{b} C o m p o s i t e}$ of neonatal morbidity, intrauterine fetal demise, and neonatal death.

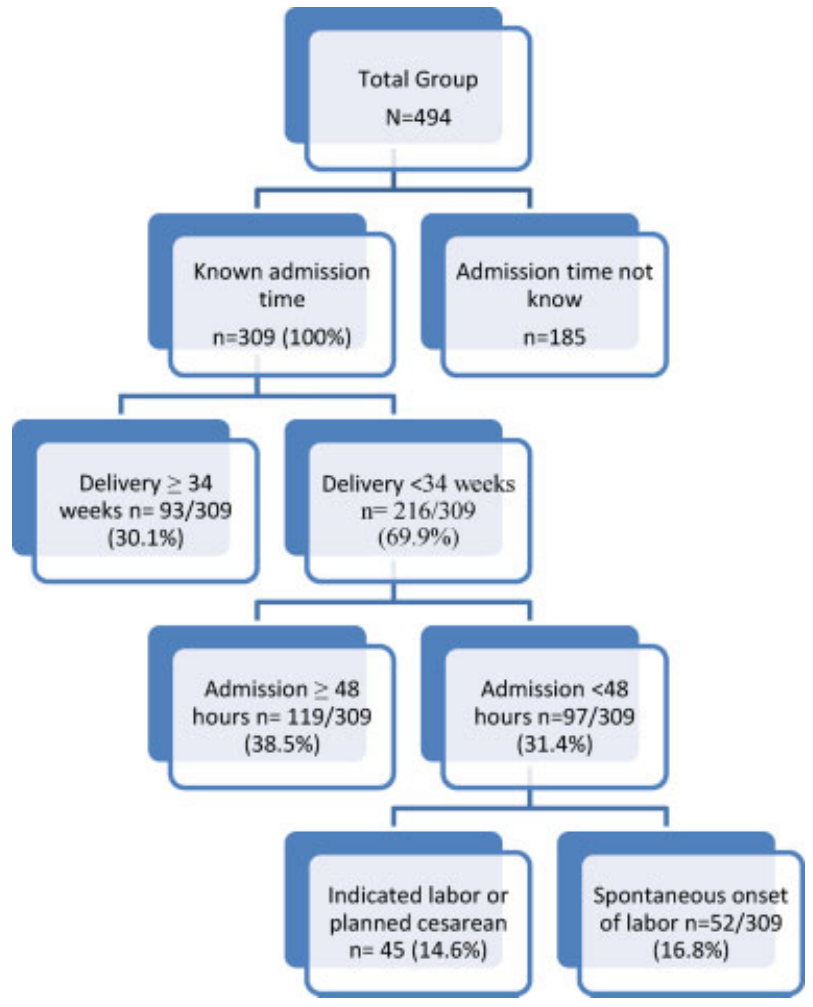

Fig. 3 The amount of women with a spontaneous preterm labor $<34$ weeks and admission $<48$ hours before labor.
Median gestational age at delivery and rates of preterm birth $<32$ weeks were significantly different for chorionicity and parity, we performed subgroup analysis for combinations of these parameters. Before 32 weeks, there was no time frame in which the risk to deliver within 1 week was more than $12 \%$, both for the total group as for the different subgroups. We recommend that untargeted steroids at a particular gestational age should not be given to women with a triplet pregnancy as steroids are, in general, only beneficial up to 34 weeks' gestation and should ideally be administered no longer than 7 to 10 days before delivery. ${ }^{13,26}$ Prophylactic administration of steroids at a particular gestational age could lead to administration of multiple courses of steroids unnecessarily. This might be beneficial for short-term neonatal outcome, but it has not been proven to be harmless in long-term pediatric follow-up. ${ }^{27,28}$ Moreover, 55\% of women who delivered $<34$ weeks were admitted for more than 48 hours before the delivery of their first child, indicating that there was enough time to administer indicated steroids targeted.

As far as we know, there is no randomized controlled trial that studied the effect of prophylactic antenatal administration of corticosteroids in women with a triplet pregnancy. Only one retrospective study by D'Amore et $\mathrm{al}^{29}$ compared neonatal outcome in 60 women with a triplet who received multiple courses of corticosteroids to the outcome of women with a triplet pregnancy who did not receive adequate steroid therapy. They found no difference in neonatal survival and 
morbidity rates between the steroid and no steroid groups. The only prognostic factor for neonatal survival in their study was gestational age at birth. ${ }^{29}$ Our findings of median gestational age at delivery in women with a triplet pregnancy are in accordance with other studies. Tandberg et $\mathrm{al}^{4}$ described a mean gestational age of 32.1 (standard deviation 3.3) weeks in 1,344 women with a triplet pregnancy, and Kawaguchi et $\mathrm{al}^{30}$ showed a median of 33 weeks (range: 23-38 weeks). Comparable to our findings, Kawaguchi et al also demonstrated that trichorionic triplets had a 1 week higher gestational age at delivery compared with monochorionic triplets ( 33 vs. 32 weeks, respectively). Spencer et $\mathrm{al}^{31}$ also showed 1 week difference in gestational age between trichorionic triplets and dichorionic triplets and found a higher neonatal morbidity rate and lower birth weight in dichorionic triplets compared with trichorionic triplets. Apart from chorionicity, we showed that parity is an important predictor for time to delivery in women with a triplet pregnancy. Fox et al ${ }^{17}$ showed that a combination of CL measurement and fFN tests are effective in the prediction of preterm delivery in asymptomatic women with a triplet pregnancy. They found a positive predictive value of $62 \%$ and a negative predictive value of $90 \%$ for delivery $<32$ weeks in women with a positive fFN test and a $\mathrm{CL}<20 \mathrm{~mm} .{ }^{17}$

This is one of the largest studies to pregnancy outcome in triplet pregnancies, thus increasing the power. Moreover, it is a nationwide study and due to the accurate registration of pregnancies and deliveries by PRN, there is low risk of selection bias. However, this study also has some limitations. First, the retrospective character, especially, in the earlier period of the study, it was not common to have a computerized administration. Therefore, it was not possible to trace chorionicity and time of hospitalization for all women. Moreover, we only have data from the period up to 2007. This was due to the fact that PRN data are only available after a few years and thereafter it took a lot of time to collect complementary data that are not registered in the PRN such as chorionicity and time of hospital admission. However, will still think the data are valuable due to the large sample size of the study and the natural course of a triplet pregnancy will not have changed much in the past years. We wanted to know if patients were admitted to the hospital in time to receive a course of antenatal steroids. Unfortunately, we had no reliable data on which women actually received steroids; therefore, we had to use a surrogate of hospital admission time which is obviously less accurate.

For the antenatal management of women with a triplet pregnancy, it is important to realize that nulliparous women and those whose triplet pregnancy contains a monochorionic component are at highest risk of preterm birth. CL measurement and fFN test can be helpful to predict preterm birth in asymptomatic women. ${ }^{17}$ However, in the study by Fox et al, the primary outcome was delivery $<32$ weeks ${ }^{17}$ and not delivery within 7 days, while this is the outcome that is necessary to know in daily clinical practice if antenatal steroid therapy should be considered. For future research on prediction of preterm birth, we, therefore, suggest to focus on shortterm delivery as outcome.

\section{Note}

This study was presented as a poster presentation at the 32nd World Congress of the Society of Maternal Fetal Medicine (SMFM), Dallas, 2012.

\section{Funding}

None.

\section{Conflict of Interest}

None.

\section{References}

1 Kupka MS, Ferraretti AP, de Mouzon J, et al; European IVFMonitoring Consortium, for the European Society of Human Reproduction and Embryology. Assisted reproductive technology in Europe, 2010: results generated from European registers by ESHRE. Hum Reprod 2014;29(10):2099-2113

2 Luke B, Brown MB. Maternal morbidity and infant death in twin vs triplet and quadruplet pregnancies. Am J Obstet Gynecol 2008; 198(4):401.e1-401.e10

3 Blondel B, Kogan MD, Alexander GR, et al. The impact of the increasing number of multiple births on the rates of preterm birth and low birthweight: an international study. Am J Public Health 2002;92(8):1323-1330

4 Tandberg A, Bjørge T, Nygård O, Børdahl PE, Skjaerven R. Trends in incidence and mortality for triplets in Norway 1967-2006: the influence of assisted reproductive technologies. BJOG 2010; 117(6):667-675

5 Revello R, De la Calle M, Moreno E, Duyos I, Salas P, Zapardiel I. Maternal morbidity on 147 triplets: single institution experience. J Matern Fetal Neonatal Med 2013;26(2):193-196

6 Petterson B, Nelson KB, Watson L, Stanley F. Twins, triplets, and cerebral palsy in births in Western Australia in the 1980s. BMJ 1993;307(6914):1239-1243

7 Zanconato G, Poggi S, Ruffo R, Gazzoni A, Padovani EM, Franchi M. Antepartum management and neonatal outcome of triplet pregnancies. Arch Gynecol Obstet 2005;271(4):320-324

8 Ziadeh SM. The outcome of triplet versus twin pregnancies. Gynecol Obstet Invest 2000;50(2):96-99

9 Kraemer B, Becker S, Kagan KO, et al. Twenty-six triplet pregnancies: a retrospective analysis. Arch Gynecol Obstet 2009;279(4): 455-461

10 Blickstein I. How and why are triplets disadvantaged compared to twins? Best Pract Res Clin Obstet Gynaecol 2004a; 18(4): 631-644

11 Weissman A, Ulanovsky I, Burke Y, Makhoul IR, Blazer S, Drugan A. Triplet pregnancies-a three-decade perspective: do we fare better? Eur J Obstet Gynecol Reprod Biol 2013;170(1):82-84

12 Joseph KS, Marcoux S, Ohlsson A, et al; Fetal and Infant Health Study Group of the Canadian Perinatal Surveillance System. Preterm birth, stillbirth and infant mortality among triplet births in Canada, 1985-96. Paediatr Perinat Epidemiol 2002;16(2):141-148

13 Roberts D, Dalziel S. Antenatal corticosteroids for accelerating fetal lung maturation for women at risk of preterm birth. Cochrane Database Syst Rev 2006;(3):CD004454

14 Ramin KD, Ogburn PL Jr, Mulholland TA, Breckle RJ, Ramsey PS. Ultrasonographic assessment of cervical length in triplet pregnancies. Am J Obstet Gynecol 1999;180(6 Pt 1):1442-1445

15 To MS, Skentou C, Cicero S, Liao AW, Nicolaides KH. Cervical length at 23 weeks in triplets: prediction of spontaneous preterm delivery. Ultrasound Obstet Gynecol 2000;16(6):515-518 
16 Poggi SH, Ghidini A, Landy HJ, Alvarez M, Pezzullo JC, Collea JV. Predictive value of transvaginal cervical length in triplet pregnancies for spontaneous preterm delivery at $<$ or $=32$ weeks. J Matern Fetal Neonatal Med 2002;12(1):46-49

17 Fox NS, Rebarber A, Roman AS, Klauser CK, Peress D, Saltzman DH. Combined fetal fibronectin and cervical length and spontaneous preterm birth in asymptomatic triplet pregnancies. J Matern Fetal Neonatal Med 2012;25(11):2308-2311

18 Elimian A, Figueroa R, Nigam S, Verma U, Tejani N, Kirshenbaum N. Perinatal outcome of triplet gestation: does prophylactic cerclage make a difference? J Matern Fetal Med 1999;8(3):119-122

19 Rebarber A, Roman AS, Istwan N, Rhea D, Stanziano G. Prophylactic cerclage in the management of triplet pregnancies. Am J Obstet Gynecol 2005;193(3 Pt 2):1193-1196

20 Caritis SN, Rouse DJ, Peaceman AM, et al; Eunice Kennedy Shriver National Institute of Child Health and Human Development (NICHD), Maternal-Fetal Medicine Units Network (MFMU). Prevention of preterm birth in triplets using 17 alpha-hydroxyprogesterone caproate: a randomized controlled trial. Obstet Gynecol 2009;113(2 Pt 1):285-292

21 Pons JC, Charlemaine C, Dubreuil E, Papiernik E, Frydman R. Management and outcome of triplet pregnancy. Eur J Obstet Gynecol Reprod Biol 1998;76(2):131-139

22 NICE Guideline. Multiple pregnancy: the management of twin and triplet pregnancies in the antenatal period. National Collaborating Centre for Women's and Children's Health. London: RCOG; 2011: 143-149

23 Bricker L. Optimal antenatal care for twin and triplet pregnancy: the evidence base. Best Pract Res Clin Obstet Gynaecol 2014;28(2): 305-317
24 PRN. The Dutch Perinatal Registry. Available at: www.perinatreg. nl. Accessed November 6, 2014

25 NVOG. The Dutch College of Obstetrics and Gynecology. Guideline threatened preterm labor (dreigende vroeggeboorte). Available at: http://nvog-documenten.nl. Accessed November 6 , 2014

26 Wilms FF, Vis JY, Pattinaja DAPM, et al. Relationship between the time interval from antenatal corticosteroid administration until preterm birth and the occurrence of respiratory morbidity. Am J Obstet Gynecol 2011;205(1):49.e1-49.e7

27 Crowther CA, McKinlay CJD, Middleton P, Harding JE. Repeat doses of prenatal corticosteroids for women at risk of preterm birth for improving neonatal health outcomes. Cochrane Database Syst Rev 2011;(6):CD003935

28 Asztalos EV, Murphy KE, Willan AR, et al; MACS-5 Collaborative Group. Multiple courses of antenatal corticosteroids for preterm birth study: outcomes in children at 5 years of age (MACS-5).JAMA Pediatr 2013;167(12):1102-1110

29 D’Amore A, Ahluwalia J, Cheema I, Prentice A, Kaptoge S, Kelsall W. The effect of antenatal corticosteroids on fetal growth, survival, and neurodevelopmental outcome in triplet pregnancies. Am J Perinatol 2004;21(1):1-8

30 Kawaguchi H, Ishii K, Yamamoto R, Hayashi S, Mitsuda N; Perinatal Research Network Group in Japan. Perinatal death of triplet pregnancies by chorionicity. Am J Obstet Gynecol 2013;209(1): 36.e1-36.e7

31 Spencer JV, Ingardia CJ, Nold CJ, Borgida AF, Herson VC, Egan JFX. Perinatal and neonatal outcomes of triplet gestations based on placental chorionicity. Am J Perinatol 2009;26(8): 587-590 